\title{
EFEK FOTODEGRADASI PADA PENGOLAHAN SURFAKTAN ANIONIK DARI LIMBAH LAUNDRY
}

\author{
Photodegradation Effect on Treatment of Anionic Surfactant \\ From Laundry Wastewater
}

\author{
Fifit Astuti
}

Program Studi Teknik Mesin, Univ. Pamulang, Tangerang Selatan, 15417

Email: fifit.astuti1@gmail.com

\begin{abstract}
ABSTRAK
Pada penelitian ini telah dipejari efek fotodegradasi pada pengolahan surfaktan anionik pada limbah laundry. Proses fotodegradasi surfaktan anionik dalam limbah laundry dilakukan dengan cara menyinari campuran limbah laundry dan serbuk fotokatalis $\mathrm{TiO}_{2}$ dalam alat yang tertutup. Pada proses ini, juga dipelajari pengaruh waktu penyinaran dan massa fotokatalis. Pengukuran kandungan surfaktan anionik yang tersisa dalam limbah selama proses fotodegradasi dilakukan dengan metode spektrofotometri UV-visibel menggunakan pengompleks metilen biru (MBAS) sesuai prosedur ISO 7875, 1996. Hasil penelitian menunjukkan bahwa penurunan surfaktan anionik dapat dicapai dari 168,64 mg/L hingga 6,38 mg/L (96,28\%) dengan waktu penyinaran 22 jam dan massa fotokatalis $\mathrm{TiO}_{2}$ optimum 50 mg. Proses fotodegradasi ini cukup menjanjikan untuk diaplikasikan dalam pengolahan limbah laundry.
\end{abstract}

Kata kunci: Surfaktan anionik, limbah laundry, fotodegradasi, $\mathrm{TiO}_{2}$

\begin{abstract}
This research was analised the effect photodegradation method to decrease anionic surfactant concentration in laundry wastewater. The investigated method was photodegradation catalyzed by $\mathrm{TiO}_{2}$. The photodegradation method of anionic surfactant in the wastewater was carried out by irradiating the mixture of the wastewater and $\mathrm{TiO}_{2}$ photocatalyst by UV-lamp. In this process, the influence of irradiation time and photocatalyst mass were studied. The concentration of anionic surfactant remaining in the waste after the process of coagulation and fotodegradation was measured by UV-Spectrophotometric method using methylene blue as complexing agent (MBAS) that follows the ISO 7875, 1996. The reseach results showed that the phothodegration process showed that the decrease of anionic surfactants can be achieved from 168,64 $\mathrm{mg} / \mathrm{L}$ up to only $6.38 \mathrm{mg} / \mathrm{L}(96,28 \%)$ when the photodegradation was done for $22 \mathrm{~h}$ using $50 \mathrm{mg}$ of $\mathrm{TiO}_{2}$. Photodegradation can be apllied in the waste treatment of laundry.
\end{abstract}

Keywords: Anionic surfactants, Laundry wastewater, Photodegradation, $\mathrm{TiO}_{2}$

\section{PENDAHULUAN}

Perkembangan usaha laundry di
berbagai tempat semakin meningkat
misalnya di kota Tangerang Selatan. Jumlah
usaha laundry yang semakin meningkat mengakibatkan semakin banyak deterjen yang digunakan, dan semakin besar volume limbah laundry yang dihasilkan. Limbah laundry mengandung bahan kimia seperti surfaktan, fosfat, ammonia dan nitrogen serta kadar padatan terlarut, kekeruhan, BOD dan COD 
tinggi [1].

Surfaktan banyak digunakan sebagai bahan pada industri deterjen, shampoo, sabun, kosmetik, tekstil, cat, polimer, minyak bumi dan lain-lain. Kebutuhan surfaktan dunia $60 \%$ digunakan untuk industri deterjen dan sabun [2]. Pada tahun 2013 data impor surfaktan negara Indonesia telah mencapai 65.624.484 $\mathrm{kg}$ [3].

Pada umumnya surfaktan yang digunakan sebagai bahan deterjen merupakan surfaktan anionik karena memiliki daya pembersih yang tinggi dan biaya produksinya rendah [4]. Surfaktan anionik bersifat toksik bagi manusia, hewan maupun tumbuhan [5]. Surfaktan dapat menyebabkan destabilisasi yang berbahaya pada flora dan fauna perairan [6]. Surfaktan jenis linear alkylbenzenesulphonates (LAS) dapat menghambat pertumbuhan mikroalga laut [7]. Penyebaran surfaktan ke lingkungan dapat merusak ekosistem lingkungan dan menyebabkan bau tidak enak [8]. Mengingat dampak negatif yang ditimbulkan oleh surfaktan limbah laundry bagi lingkungan, maka perlu dilakukannya pengembangan metode pengolahan limbah laundry untuk menurunkan kandungan surfaktan dari limbah laundry sebelum dibuang ke lingkungan. Berdasarkan analisa tersebut maka pada penelitian ini, perlu dilakukan pengolahan limbah laundry dengan merode fotodegradasi terkatalis $\mathrm{TiO}_{2}$.

\section{BAHAN DAN METODE}

Proses fotodegradasi surfaktan anionik pada limbah laundry dilakukan dengan sistem batch dalam reaktor yang dilengkapi dengan

lampu UV dan plat pengaduk magnet seperti pada Gambar 1. Pada penelitian ini parameter yang dipelajari pada proses fotodegradasi terkatalis $\mathrm{TiO}_{2}$ yaitu pengaruh massa fotokatalis $\mathrm{TiO}_{2}$ dan lamanya waktu fotodegradasi terhadap efektivitas fotodegradasi.

Pengaruh massa fotokatalis $\mathrm{TiO}_{2}$ dipelajari dengan melakukan fotodegradasi pada berbagai variasi massa $\mathrm{TiO}_{2}$. Pengaruh waktu fotodegradasi dipelajari dengan melakukan fotodegradasi menggunakan massa $\mathrm{TiO}_{2}$ optimum, dengan variasi waktu penyinaran 16, 18, 20, 22, 24, dan 26 jam.. Sebagai pembanding, dilakukan pula fotodegradasi untuk mengetahui pengaruh fotokatalitik $\mathrm{TiO}_{2}$ dan sinar UV terhadap efektivitas fotodegradasi surfaktan dengan kondisi sebagai berikut:

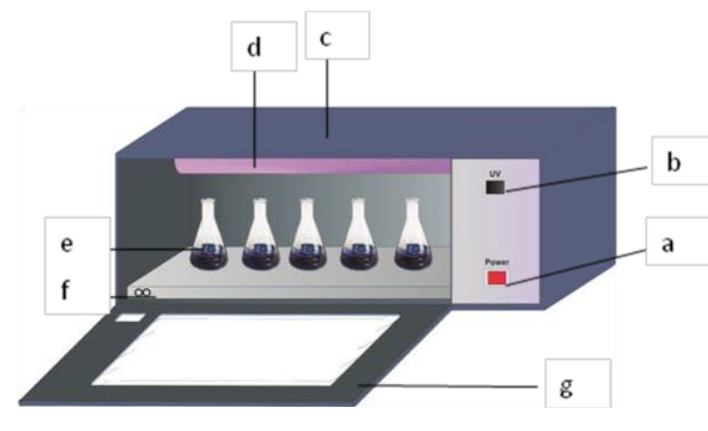
a. Saklar Listrik
b. Saklar UV
c. Kotak reaktor
d. Lampu UV
e. Erlenmeyer berisi larutan
f. Plat pengaduk magnetik
g. Tutup reaktor

Gambar 1. Reaktor pada proses fotodegradasi 


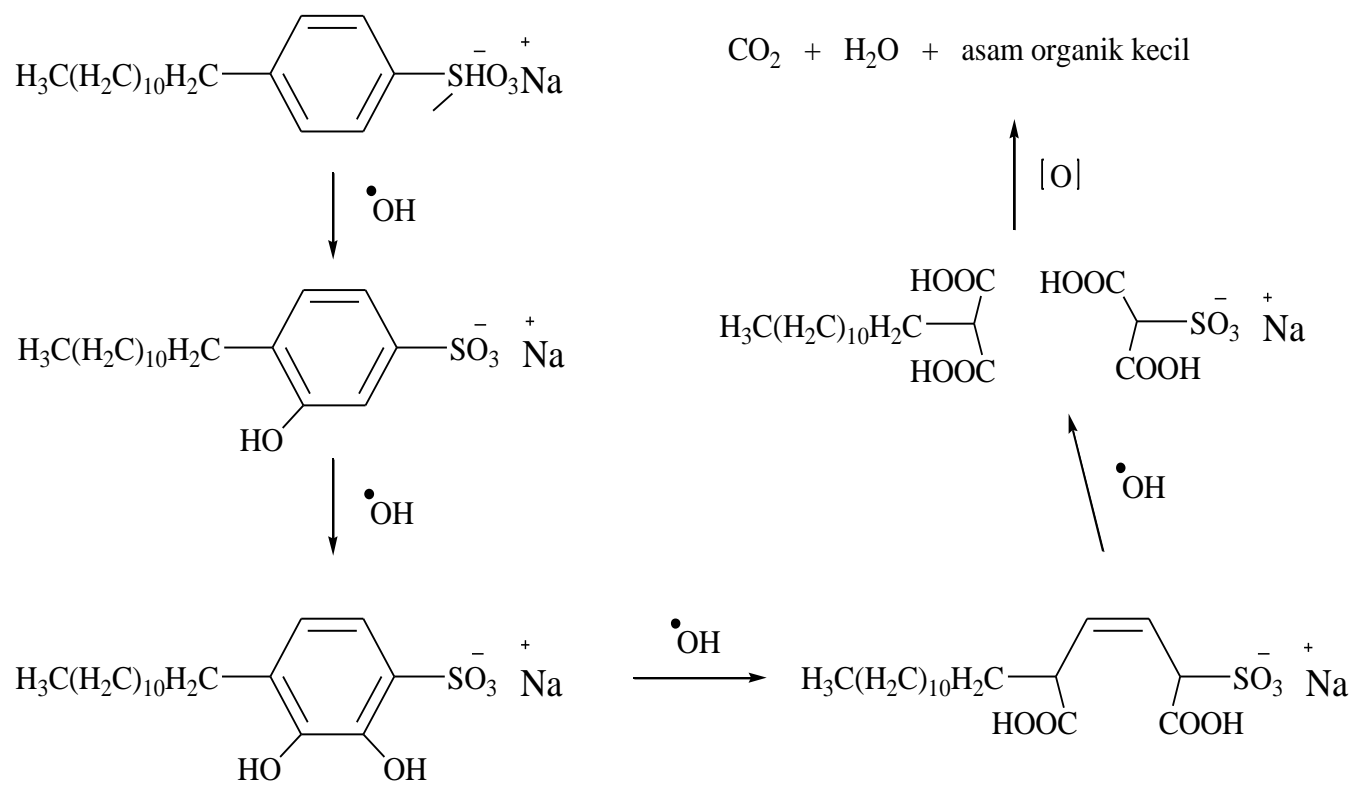

Gambar 2. Skema reaksi fotodegradasi DBS terkatalis $\mathrm{TiO}_{2}$ [9]

1. Larutan limbah laundry sebanyak 50 $\mathrm{mL}$ dengan penambahan fotokatalis $\mathrm{TiO}_{2}$ yang disinari lampu UV.

2. Larutan limbah laundry sebanyak $50 \mathrm{~mL}$ tanpa penambahan fotokatalis $\mathrm{TiO}_{2}$ yang disinari lampu UV.

3. Larutan limbah laundry sebanyak 50 $\mathrm{mL}$ dengan penambahan fotokatalis $\mathrm{TiO}_{2}$ yang diaduk dalam ruang gelap (tanpa penyinaran)

Sebelum metode ini diterapkan dalam penentuan konsentrasi surfaktan anionik hasil fotodegradasi, dilakukan penentuan kondisi optimum kompleks larutan DBS-MB yang terbentuk untuk memperoleh hasil analisis yang tepat. Optimasi yang dilakukan meliputi panjang gelombang dan waktu kestabilan senyawa kompleks yang terbentuk.

Analisis konsentrasi surfaktan sebelum dan sesudah fotodegradasi dilakukan secara spektofotemetri menggunakan metode Methylene Blue Active Substances (MBAS). Hasil ekstraksi selanjutnya dianalisis menggunakan spektrofotometer UV-Visibel pada panjang gelombang $656 \mathrm{~nm}$.

\section{HASIL DAN PEMBAHASAN}

Proses fotodegradasi pada penelitian ini dilakukan dengan cara menyinari campuran sampel dengan lampu UV dalam reaktor tertutup. Penyinaran ini berfungsi sebagai sumber energi foton (hv) agar reaksi fotodegradasi surfaktan anionik dapat berlangsung. Pada proses ini, juga dilakukan pengadukan menggunakan pengaduk magnet (magnetic stirer) sehingga proses fotodegradasi dapat berlangsung secara efektif.

Selama proses penyinaran terbentuk radikal $\mathrm{OH}$ dari $\mathrm{TiO}_{2}$ dalam larutan yang dikenai radiasi foton (hv) sinar uv, maka elektron pada pita valensi akan tereksitasi ke pita konduksi membentuk lubang pada pita valensi $(\mathrm{hvb}+)$ dan elektron pada pita konduksi (ecb -). Lubang pada pita valensi pada permukaan $\mathrm{TiO}_{2}$ inilah yang dapat membentuk radikal $\mathrm{OH}(\cdot \mathrm{OH})$.

$$
\begin{aligned}
& \mathrm{TiO}_{2}+h_{p} \rightarrow \mathrm{TiO}_{2}\left(h_{p b}{ }^{+}+\mathrm{e}_{\mathrm{cb}}\right) \\
& h_{p b}{ }^{+}+>\mathrm{Ti}^{\mathrm{IV}} \mathrm{OH} \rightarrow\left(>\mathrm{Ti}^{\mathrm{IV}} \mathrm{OH}^{\bullet}\right)^{+}
\end{aligned}
$$


dimana $(>$ TilVOH $\bullet)+$ adalah radikal hidroksil yang terperangkap pada permukaan lubang pita valensi. Pembentukan radikal $\mathrm{OH}$ selain berasal dari fotokatalis $\mathrm{TiO}_{2}$ juga dapat berasal dari fotolisis $\mathrm{H}_{2} \mathrm{O}$ sebagai pelarut.

$$
\mathrm{H}_{2} \mathrm{O}+h v \rightarrow \cdot \mathrm{OH}+\mathrm{H}^{+}+\mathrm{e}^{-}
$$

Mekanisme reaksi fotodegradasi surfaktan terkatalis $\mathrm{TiO}_{2}$ disajikan pada Gambar 2.

Gambar 3. menunjukkan bahwa kenaikan massa fotokatalis $\mathrm{TiO}_{2}$ memberikan kenaikan efektivitas fotodegradasi dan mencapai maksimum dengan penggunaan 50 mg $\mathrm{TiO}_{2}$. Penggunaan fotokatalis dengan massa yang lebih besar menyebabkan penurunan fotodegradasi surfaktan dalam limbah laundry. Semakin besar massa fotokatalis $\mathrm{TiO}_{2}$ yang digunakan maka radikal $\mathrm{OH}$ yang terbentuk semakin banyak sehingga menghasilkan fotodegradasi surfaktan yang semakin efektif.

Pada penggunaan fotokatalis $\mathrm{TiO}_{2}$ dengan massa yang sangat besar dapat meningkatkan kekeruhan dalam larutan. Kekeruhan ini dapat menghalangi masuknya sinar UV ke dalam sistem reaksi sehingga interaksi antara sinar dengan fotokatalis kurang efektif. Akibatnya pembentukan radikal $\mathrm{OH}$ juga semakin berkurang, sehingga efektivitas fotodegradasi surfaktan anionik menurun.

Hasil analisa pengaruh waktu penyinaran dalam proses fotodegradasi yang diperoleh ditunjukkan pada pada Gambar 4. Pada Gambar 4. dapat dilihat bahwa waktu penyinaran yang semakin lama memberikan peningkatan efektivitas fotodegradasi surfaktan anionik dalam limbah laundry hingga mencapai maksimum, yaitu selama 22 jam. Namun efektivitas fotodegradasi mengalami penurunan untuk waktu penyinaran yang lebih lama dari 22 jam. Semakin lama waktu penyinaran, interaksi antara fotokatalis $\mathrm{TiO}_{2}$ dengan sinar semakin efektif sehingga semakin banyak energi foton yang diserap oleh fotokatalis dan molekul air. Hal ini menghasilkan jumlah radikal $\mathrm{OH}$ yang semakin banyak. Selain itu semakin lama waktu penyinaran maka interaksi antara radikal $\mathrm{OH}$ dengan surfaktan anionik juga semakin efektif. Hal ini yang memberikan peningkatan efektivitas fotodegradasi surfaktan anionik dalam limbah laundry.

Gambar 4 juga menunjukkan bahwa efektivitas fotodegradasi surfaktan anionik dengan waktu penyinaran lebih 22 jam mengalami penurunan meskipun relatif kecil. Untuk proses penyinaran yang sangat lama telah dihasilkan produk terdegradasi yang semakin banyak sehingga produk tersebut dapat menghalangi interaksi antara fotokatalis dengan sinar UV serta fotokatalis dengan surfaktan anionik yang belum terdegradasi. Akhirnya proses fotodegradasi menjadi kurang efektif.

\section{Kesimpulan}

Berdasarkan hasil penelitian yang telah dilakukan, dapat disimpulkan bahwa metode fotodegradasi terkatalis $\mathrm{TiO}_{2}$ menurunkan kandungan surfaktan dalam limbah laundry dari 168,64 mg/L menjadi $6,38 \mathrm{mg} / \mathrm{L}$ $(96,28 \%)$ pada $50 \mathrm{~mL}$ volume limbah dengan massa fotokatalis $\mathrm{TiO}_{2}$ yang optimum $50 \mathrm{mg}$ dan waktu penyinaran optimum selama 22 jam. Proses fotodegradasi ini cukup menjanjikan untuk diaplikasikan dalam pengolahan limbah laundry. 


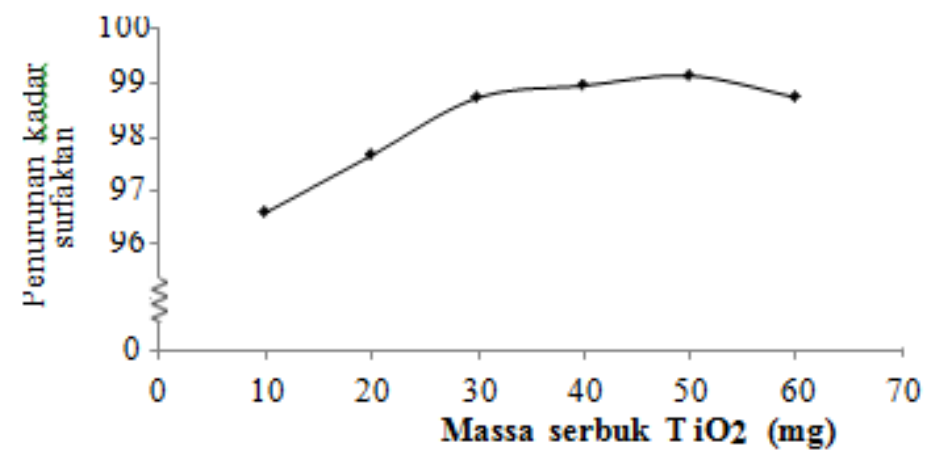

Gambar 3. Pengaruh massa serbuk $\mathrm{TiO}_{2}$ terhadap penurunan kandungan surfaktan anionik limbah laundry

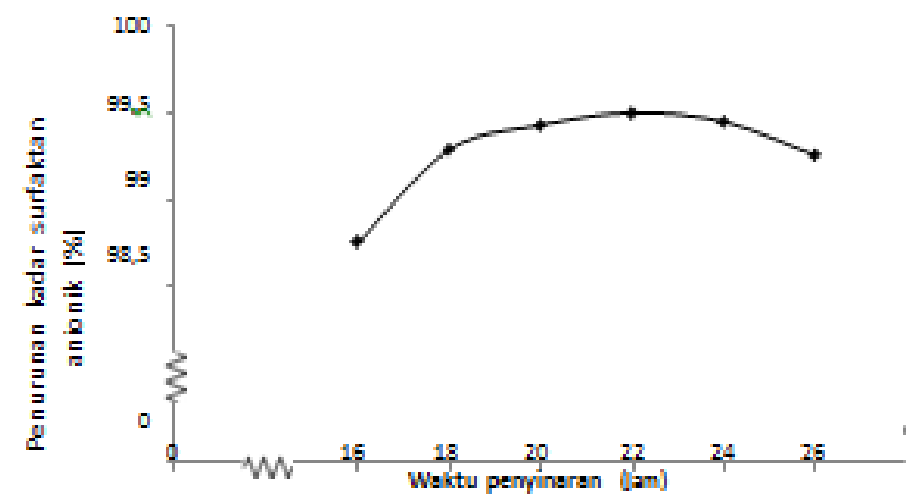

Gambar 4. Pengaruh waktu penyinaran terhadap efektivitas penurunan kandungan surfaktan anionik dalam limbah laundry 


\section{DAFTAR PUSTAKA}

[1] Ahmad, J., dan El-Dessouky, H., (2008), Design of a modified low cost Treatment system for the recycling and reuse of laundry waste water, Resources, Conservation and Recycling, 52, 973-978

[2] Suryani, A., 2013, Mengangkat Minyak Bumi dengan Surfaktan Sawit, Makalah, Fakultas Pertanian, Institut Pertanian Bogor, Bogor

[3] Irawan, Y., 2014, Tantangan Industri Kimia di dalam Pengadaan Bahan Kimia Enhanced Oil Recovery (EOR), Diklat Panel EOR BKKPII-IATMI 2014, Lembaga Ilmu Pengetahuan Indonesia, Jakarta.

[4] Holmberg, K., Jonsson, B., Kronberg, B., Lindman, B., 2003. Surfactants and Polymers in Aqueous Solution, second ed. Wiley, Chichester, England.

[5] Adak, A., Bandyopadhyay, M., Pal A., 2005, Removal of Anionic Surfactant from Wastewater by Alumina:a Case Study, Colloids Surf., A, 254, 165-171.

[6] Beltrán-Heredia, J., Martín J.S., Moreno M.B., 2012, Long-Chain Anionic Surfactants in Aqueous Solution. Removal by Moringa oleifera Coagulant, Chem. Eng. J., 180, 128136.

[7] Debelius, B.,Forja, J.M., Valls, A.D., Lubia'n, L.M., 2008, Effect of Linear Alkylbenzene Sulfonate (LAS) and Atrazineon Marine Microalgae, Mar. Pollut. Bull., 57, 559-568.

[8] Hanif, N.M., Adnan, S.N.N., Latif, M.T., Zakaria, Z., Abdulhanand, P., and
Othman, R., 2012, The Composition of Surfactants in River Water and its Influence to The Amount of Surfactants in Drinking Water, World Appl. Sci. J., 8, 17, 970-975.

[9] Naldoni, A., Schiboula, A., Bianchi, C.L., and Bremner, D.H., Mineralisation of Surfactants Using Ultrasound and Advanced Fenton Process, Water Air Soil Pollut., 215, 487-495 